\title{
Evaluation of Partial Breast Reirradiation with Intraoperative Radiotherapy after Prior Thoracic Radiation: A Single-Institution Report of Outcomes and Toxicity
}

\author{
Christine Chin', Priya Jadeja², Bret Taback², David P. Horowitz', \\ Sheldon M. Feldman ${ }^{3}$, Richard $\mathrm{Ha}^{4}$ and Eileen P. Connolly ${ }^{1 *}$
}

\begin{abstract}
${ }^{1}$ Radiation Oncology, NYP-Columbia University Medical Center, New York, NY, United States, ${ }^{2}$ Breast Surgery, NYPColumbia University Medical Center, Herbert Irving Pavilion, New York, NY, United States, ${ }^{3}$ Breast Surgery and Breast Surgical Oncology, Montefiore M-E Center for Cancer Care, Bronx, NY, United States, ${ }^{4}$ Radiology, NYP-Columbia University Medical Center, Herbert Irving Pavilion, New York, NY, United States
\end{abstract}

OPEN ACCESS

Edited by:

William Small Jr.,

Stritch School of Medicine,

United States

Reviewed by:

Andrew O. Wahl,

University of Nebraska Medical

Center, United States

John Austin Vargo,

West Virginia University

Hospitals, United States

${ }^{*}$ Correspondence:

Eileen P. Connolly

epc2116@cumc.columbia.edu

Specialty section:

This article was submitted to Radiation Oncology, a section of the journal

Frontiers in Oncology

Received: 28 March 2017

Accepted: 31 July 2017

Published: 28 August 2017

Citation:

Chin C, Jadeja P, Taback B, Horowitz DP, Feldman SM, Ha R and Connolly EP (2017) Evaluation of Partial Breast Reirradiation with Intraoperative Radiotherapy after

Prior Thoracic Radiation:

A Single-Institution Report of

Outcomes and Toxicity.

Front. Oncol. 7:175

doi: 10.3389/fonc.2017.00175
Introduction: Mastectomy is the current standard of care for ipsilateral breast tumor recurrences after prior whole breast irradiation (WBI). We report our single-institution experience with breast-conserving surgery (BCS) followed by intraoperative radiotherapy (IORT) as an alternative to salvage mastectomy for new or recurrent breast cancers that develop in the setting of prior thoracic radiation.

Methods: We performed an IRB-approved retrospective review of patients treated with breast IORT between September 2013 and November 2016. We identified 12 patients who declined salvage mastectomy for their breast cancer after prior thoracic radiation. IORT was delivered using the Intrabeam ${ }^{\mathrm{TM}}$ device (Carl Zeiss, Germany). A dose of 20 Gy was prescribed to the lumpectomy cavity surface using $50 \mathrm{kV}$ X-rays. We graded both acute and late treatment-related breast toxicities using the National Cancer Institute Common Terminology Criteria for Adverse Events version 4.0. Local control, mastectomy-free survival, distant metastasis, and overall survival were determined.

Results: Our study included nine patients who developed a new or recurrent ipsilateral breast cancer after prior WBI for early-stage breast cancer, two patients with primary breast cancer after mantle-field radiation for Hodgkin's lymphoma, and one patient with a synchronous stage III non-small cell lung cancer treated with definitive radiation to the ipsilateral lung and mediastinum. The median time from prior radiation to presentation was 18 years (range: 2 months to 46 years). All patients successfully underwent partial breast reirradiation with IORT and were able to preserve their breast. At a median follow-up of 14 months (4-25 months), there were no local or distant recurrences. There was a single non-cancer-related death. In the acute setting, we observed grade 1 toxicity in 58\% $(n=7)$, grade 2 toxicity in $17 \%(n=2)$, and no grade 3 or higher toxicity. In the late setting, at least 3 months after IORT, we observed grade 1 hyperpigmentation and/or fibrosis in 50\% $(n=6)$, symptomatic seroma requiring drainage in 33\% $(n=4)$. A single patient developed an abscess requiring hospitalization and intravenous antibiotic therapy. 
Conclusion: BCS with IORT is a feasible salvage option for patients who present with localized breast cancer after prior thoracic radiation treatment. Continued follow-up of these patients is warranted given the incidence of delayed toxicity.

Keywords: breast, accelerated partial breast irradiation, intraoperative radiation therapy, recurrence, reirradiation, toxicity

\section{INTRODUCTION}

Based on a number of large randomized trials, the estimated 10 -year rate of an isolated ipsilateral breast tumor recurrence (IBTR) after breast-conserving therapy is approximately $10 \%$ $(1,2)$. At the time of local recurrence the current standard of care is salvage mastectomy given the unacceptable toxicity to normal tissues with repeat whole breast irradiation (WBI). Local excision alone of an IBTR results in subsequent local recurrence in approximately $35 \%$ of patients based on retrospective series (3-8). Interestingly, in women who develop late local recurrences more than 5 years after treatment of their primary disease, disease-free, and overall survival is not significantly different compared to women who do not experience an $\operatorname{IBTR}(4,9,10)$. The prolonged interval until recurrence reflects a favorable tumor biology, and retrospective studies report no difference in survival between patients who undergo salvage mastectomy and breast-conserving surgery (BCS) for small, localized recurrences $(10,11)$. Given that many IBTRs are detected early on surveillance-imaging, many patients desire a breast-conserving option at the time of recurrence. Breast-conserving therapies have therefore become increasingly popular in treating these patients.

Accelerated partial breast irradiation (APBI) is a novel technique that offers the opportunity to limit radiation dose to previously irradiated breast tissue while improving rates of local control after BCS (12-16). There have been a limited number of small retrospective and prospective studies examining the use of APBI after local excision of an IBTR in the setting of prior radiation using various dose fractionations and delivery techniques (17-23). The use of intraoperative radiation therapy (IORT) to deliver a single, high-dose radiation to the lumpectomy surface at the time of surgery has been compared to adjuvant whole breast radiotherapy in the treatment of unifocal, early-stage breast cancers with non-inferior results (13). Its use in the setting of reirradiation has been reported with acceptable toxicity and cosmesis in small retrospective studies $(13,24,25)$. Here, we report our single-institution experience with partial breast reirradiation (PBrI) with IORT after BCS in patients who decline salvage mastectomy.

\section{MATERIALS AND METHODS}

\section{Patient Eligibility}

We performed a retrospective review approved by the Columbia University Institutional Review Board of 228 patients treated with breast IORT between September 1, 2013, and November 31,2016 . Written informed consent was obtained from research participants. Patients were included in this study if they had developed a unifocal IBTR or new primary breast cancer (PBC) in the setting of prior WBI for early-stage breast cancer or a PBC after definitive thoracic radiation for another primary malignancy and declined salvage mastectomy. IBTR was defined as a breast tumor recurrence with the same histology and location as the initial PBC.

\section{Radiation Treatment}

Intraoperative radiotherapy was delivered using the Intrabeam ${ }^{\mathrm{TM}}$ device (Carl Zeiss, Oberkochen, Germany) at the time of lumpectomy. A spherical applicator was chosen at the radiation oncologist and operating surgeon's discretion to most appropriately fit the lumpectomy cavity. Ultrasound was used to confirm a minimum skin to applicator margin of at least $10 \mathrm{~mm}$. A medical physicist was present to confirm delivery of 20 Gy to the surface of the lumpectomy cavity using $50 \mathrm{kV}$ X-rays.

\section{End Point Analysis}

Patients were encouraged to follow-up at 2 weeks after surgery and at least every 6 months for the first year after treatment. End points of local control, mastectomy-free survival, distant metastasis, and overall survival were determined from the time of IORT. Acute and long-term side effects including breast pain, dermatitis, fibrosis, seroma, and infection were graded according to the National Cancer Institute Common Terminology Criteria for Adverse Events (CTCAE) version 4.0.

\section{RESULTS}

\section{Patient and Primary Tumor Characteristics}

The median age of our patients at the time of recurrence was 65 years old (range: $52-85$ years). The median time from prior external beam radiation to biopsy-proven recurrence was 18 years (range: 2 months to 46 years). Nine patients developed an IBTR or new PBC after prior WBI for early-stage breast cancer, 2 patients with a new PBC after mantle-field radiation for Hodgkin's lymphoma, and 1 patient with a synchronous diagnosis of stage III non-small cell lung cancer (NSCLC) treated with definitive radiation to the ipsilateral lung and mediastinum. Only one patient with the synchronous diagnosis of stage III NSCLC and breast cancer underwent breast IORT at an interval of less than 1 year from the time of prior definitive radiation. Further available details of patient primary tumor and treatment characteristics are presented in Table $\mathbf{1}$.

\section{Pathologic Findings}

Based on final pathology, the median tumor size was $0.55 \mathrm{~cm}$ (range: 0-3.9 cm). All patients with invasive primaries were hormone receptor positive, defined as $\geq 1 \%$ staining of the estrogen 
TABLE 1 | Primary tumor and treatment characteristics.

\begin{tabular}{|c|c|c|c|c|c|}
\hline Patient & Age at initial diagnosis (years) & $\begin{array}{c}\text { Histology of } \\
\text { primary disease }\end{array}$ & Subtype & Prior radiation details & Prior adjuvant therapy \\
\hline 1 & 53 & IDC & $\mathrm{ER} / \mathrm{PR}+$ & WBI 50 and 15 Gy boost & CMF, tamoxifen \\
\hline 2 & 38 & Hodgkin's lymphoma & - & Mantle field 40 Gy & - \\
\hline 3 & 44 & DCIS & $\mathrm{ER} / \mathrm{PR}+$ & WBI dose unknown & Tamoxifen \\
\hline 4 & 76 & IDC & ER/PR+ & WBI dose unknown & $\begin{array}{l}\text { Anastrazole started but } \\
\text { did not tolerate }\end{array}$ \\
\hline 5 & 49 & DCIS & $\mathrm{ER} / \mathrm{PR}+$ & WBI 50 and 15 Gy boost & None \\
\hline 6 & 52 & NSCLC & - & Right lung and mediastinum IMRT 66 Gy ${ }^{b}$ & - \\
\hline 7 & 43 & IDC & TNBC & WBI 50.4 and 10 Gy boost & ddAC \\
\hline 8 & 20 & Hodgkin's lymphoma & - & Mantle field 40 Gy & - \\
\hline 9 & 53 & DCIS & ER/PR- & WBI 50.4 and 10 Gy boost & None \\
\hline 10 & 51 & IDC & $\mathrm{ER} / \mathrm{PR}+$ & WBI, 50.4 and 12 Gy boosta & A/T/bevacizumab/lupron ${ }^{b}$ \\
\hline 11 & 59 & IDC & ER/PR+ & WBI dose unknown & Tamoxifen \\
\hline 12 & 54 & IDC & $\mathrm{ER} / \mathrm{PR}+$ & WBI dose unknown & None \\
\hline
\end{tabular}

IDC, invasive ductal carcinoma; ER, estrogen receptor; PR, progesterone receptor; NSCLC, non-small cell lung cancer; IMRT, intensity modulated radiation therapy; CMF, cyclophosphamide, methotrexate, fluorouracil; ddAC, dose dense doxorubicin, cyclophosphamide; AT, doxorubicin, paclitaxel.

${ }^{a}$ Patient was treated with neoadjuvant chemotherapy and definitive radiation therapy for her initial primary. ${ }^{b}$ Therapy given in the neoadjuvant setting.

${ }^{b}$ Right breast mean dose 10.9 Gy, max point dose 59.6 Gy.

TABLE 2 | Patient treatment characteristics.

\begin{tabular}{|c|c|c|c|c|c|c|c|c|}
\hline Patient & $\begin{array}{c}\text { Age at recurrence } \\
\text { (years) }\end{array}$ & $\begin{array}{c}\text { Time to recurrence }{ }^{b} \\
\text { (years) }\end{array}$ & $\begin{array}{l}\text { Histology of } \\
\text { breast tumor }\end{array}$ & $\begin{array}{l}\text { Type of } \\
\text { recurrence }\end{array}$ & Subtype & $\begin{array}{c}\text { IBTR } \\
\text { size }(\mathrm{cm})\end{array}$ & $\begin{array}{l}\text { Lymph node } \\
\text { sampling }\end{array}$ & $\begin{array}{c}\text { Adjuvant systemic } \\
\text { therapy }\end{array}$ \\
\hline 1 & 78 & 25 & IDC & IBTR & ER/PR+ & 0.2 & $0 / 3$ & Exemestane \\
\hline 2 & 74 & 36 & IDC & PBC & $\mathrm{PR}+$ & 0.2 & - & Intolerance of Al \\
\hline 3 & 60 & 16 & DCIS & IBTR & $\mathrm{PR}+$ & $0^{a}$ & - & None \\
\hline 4 & 85 & 9 & IDC & IBTR & $\mathrm{ER} / \mathrm{PR}+$ & 0.4 & - & None, previous intolerance of $\mathrm{Al}$ \\
\hline 5 & 78 & 29 & DCIS & IBTR & ER/PR+ & 0.6 & - & Tamoxifen \\
\hline 6 & 52 & 0.2 & IDC & PBC & $\mathrm{ER} / \mathrm{PR}+$ & 3.5 & $5 / 20$ & TC, anastrazole \\
\hline 7 & 64 & 21 & IDC & SBC & PR+ & 1.1 & $0 / 2$ & Anastrazole \\
\hline 8 & 66 & 46 & DCIS & PBC & ER/PR- & 0.5 & - & None \\
\hline 9 & 64 & 11 & IDC & SBC & $\mathrm{ER} / \mathrm{PR}+$ & 1.5 & $0 / 3$ & Anastrazole but did not tolerate \\
\hline 10 & 55 & 5 & Mixed IDC/ILC & IBTR & ER/PR+ & 1.9 & $0 / 14$ & Letrozole \\
\hline 11 & 78 & 19 & IDC & $\mathrm{SBC}$ & $\begin{array}{c}\mathrm{ER} / \mathrm{PR}+ \\
\mathrm{HER} 2+\end{array}$ & 3.9 & - & Anastrazole, trastuzumab \\
\hline 12 & 62 & 8 & IDC & SBC & $\begin{array}{c}\mathrm{ER} / \mathrm{PR}+ \\
\mathrm{HER} 2+\end{array}$ & 0.4 & $0 / 1$ & Anastrazole, trastuzumab \\
\hline
\end{tabular}

IBTR, ipsilateral breast tumor recurrence; SBC, second breast cancer defined as an ipsilateral breast cancer of a different histology from the initial primary breast cancer; PBC, primary breast cancer in the setting of another prior malignancy; Al, aromatase inhibitor; TC, docetaxel and cyclophosphamide.

${ }^{a}$ Patient 3 had no residual disease at the time of lumpectomy.

'Interval time from prior diagnosis to biopsy-proven breast recurrence.

and/or progesterone receptor by immunohistochemistry (26). Two patients were HER2/neu positive per American Society of Clinical Oncology/CollegeofAmericanPathologists(ASCO/CAP)guideline recommendations (27). One of two patients with ductal carcinoma in situ (DCIS) was hormone receptor negative. Five patients underwent axillary sampling at the time of surgery for their IBTR. One patient was found to have involved sentinel lymph nodes and underwent completion of an axillary lymph node dissection. All patients with invasive primaries were found to have negative margins with no tumor on the final inked margin. One patient with DCIS was found to have a final close margin of $1 \mathrm{~mm}$ with no further re-excision. A summary of these findings is shown in Table 2.

\section{IORT Details}

The median applicator size used in our cohort of patients was $3.0 \mathrm{~cm}$ (range: $3.0-3.5 \mathrm{~cm}$ ). All patients were prescribed 20 Gy to the lumpectomy surface using $50 \mathrm{kV} \mathrm{X}$-rays. The median treatment time was $24.2 \mathrm{~min}$ (range: 17.1-24.7 $\mathrm{min}$ ). The median applicator to skin distance was superiorly $15.3 \mathrm{~mm}$ (range: $5.1-23.0 \mathrm{~mm}$ ), inferiorly $13.9 \mathrm{~mm}$ (range: $8.3-21.9 \mathrm{~mm}$ ), medially $19.4 \mathrm{~mm}$ (range: 11.0-29.7 mm), and laterally $13.9 \mathrm{~mm}$ (range: 6.3-22.1 mm).

\section{Adjuvant Systemic Therapy}

All patients with hormone receptor-positive disease were recommended adjuvant hormonal therapy. All patients were compliant with therapy except three patients due to intolerance. One patient with disease metastasis to the axilla was treated with adjuvant docetaxel and cyclophosphamide chemotherapy. Two patients with HER2-positive invasive disease received adjuvant trastuzumab therapy.

\section{Outcomes and Toxicity}

At a median follow-up of 14 months (range: 4-25 months) there were no events of local or distant recurrence, and all women 
were able to preserve their breast. There was a single non-breast cancer-related death due to heart failure. In the acute setting, we observed grade 1 dermatitis in $25 \%(n=3)$, grade 1 breast pain in $8 \%(n=1)$, grade 1 seroma in $25 \%(n=3)$, grade 2 seromas requiring drainage in $17 \%(n=2)$, and grade 2 infection in $8 \%$ $(n=1)$. No grade 3 or higher acute toxicity was observed. In the late setting, defined as 3 months after treatment with IORT, we observed grade 1 hyperpigmentation and/or fibrosis in 50\% $(n=6)$, grade 1 seromas in $8 \%(n=1)$, persistent grade 2 seromas in $33 \%(n=4)$, and grade 2 infection in $17 \%(n=2)$. There was a single patient who developed a grade 3 abscess requiring hospitalization and intravenous antibiotic therapy. There were no grade 2 or higher toxicity for the patient who underwent breast IORT within a year of prior definitive RT. Details of patient toxicity regarding breast seroma formation and infection are presented in Table 3.

\section{DISCUSSION}

In our single-institution experience, all 12 of our patients were able to successfully undergo local excision of their breast cancer followed by IORT with acceptable toxicity and preserve their breast. After a median follow-up of 14 months, there were no events of local or distant recurrence. In the late setting after treatment, we observed a significant incidence of persistent grade 2 seromas requiring drainage and antibiotic therapy. In the current literature, there are conflicting accounts of postAPBI seroma formation using various brachytherapy techniques. Evans et al. reported persistent seromas in about $75 \%$ of patients (greater than 6 months after treatment) treated with APBI using MammoSite ${ }^{\circledR}$. Evaluating various dosimetric, clinical, and treatment-related variables, higher body weight was the only significant variable that correlated positively with seroma formation (28). On the contrary, Kraus-Tiefenbacher reported no difference in the rate of palpable seromas between patients who underwent BCS with or without IORT at the time of lumpectomy. While radiographically detected seromas were higher in the IORT group ( 81 vs. $52 \%, p<0.001$ ), the rate of palpable clinically significant seromas was not different. In their analysis, the addition of adjuvant chemotherapy correlated with higher rates of seromas detected on follow-up CT imaging (contingency coefficient $0.22, p=0.003$ ) (29). The higher incidence of seromas we observed in our study may reflect the lower tolerance of normal tissue in the reirradiation setting.

There has been one other published report of PBrI with IORT in a cohort of 17 patients who developed localized breast recurrences after previous external beam radiation (25). Overall, with a median follow-up of 26 months there were no reported local recurrences. Acute toxicity consisted mainly of mild induration of the tumor bed, and there were no instances of grade 3 or 4 toxicity. Interestingly, in comparison to our study, a larger median size applicator was used to treat the lumpectomy cavity (median $4.0 \mathrm{~cm}$, range: $2.5-5.0 \mathrm{~cm}$ ) and 3 of the 17 patients treated with $\geq 4.5 \mathrm{~cm}$ applicator were prescribed a lower dose of 14.7 Gy to the lumpectomy surface. While both of our cohorts are small, the difference in our reported experiences highlights the importance of applicator selection. Larger applicator selection may help to optimize apposition of the applicator against surrounding breast tissue and improve dose homogeneity at the tissue-applicator interface.

There are a number of single-institution studies that have reported on the toxicity and outcomes of PBrI. Deutsch et al. reported on their experience with PBrI using external beam electrons to cover the involved breast quadrant to $50 \mathrm{~Gy}$ in $2 \mathrm{~Gy}$ per daily fraction. They reported a recurrence free rate of $77 \%$ at 52-month follow-up, and overall good cosmesis with mainly skin pigmentation changes (14). Interstitial brachytherapy has been used by several institutions, reporting late toxicity of grade 3 fibrosis in up to $10-16 \%$ of patients $(15,17,19,20)$. Freedom from a second local recurrence at a median follow-up of 5 years was $89-93 \%$. Existing studies support the efficacy and safety of PBrI to treat IBTR. To date, however, there is no clear optimal delivery technique or dose fractionation. RTOG 1014 is the most recent prospective trial examining the safety and efficacy of PBrI for IBTR after prior WBI using 3D-conformal external beam radiation. Their preliminary outcomes were reported at the recent American Society for Radiation Oncology conference, describing a 3 -year subsequent IBTR of 3.7\%, DMFS and

TABLE 3 | CTCAE graded treatment toxicity.

\begin{tabular}{|c|c|c|c|c|c|c|c|c|c|c|}
\hline Patient & $\begin{array}{c}\text { Dermatitis } \\
\text { (acute) }\end{array}$ & $\begin{array}{c}\text { Skin changes } \\
\text { (late) }\end{array}$ & $\begin{array}{c}\text { Breast infection } \\
\text { (acute) }\end{array}$ & $\begin{array}{c}\text { Breast infection } \\
\text { (late) }\end{array}$ & $\begin{array}{c}\text { Seroma } \\
\text { (acute) }\end{array}$ & $\begin{array}{c}\text { Seroma } \\
\text { (late) }\end{array}$ & $\begin{array}{l}\text { Fibrosis } \\
\text { (acute) }\end{array}$ & $\begin{array}{l}\text { Fibrosis } \\
\text { (late) }\end{array}$ & $\begin{array}{c}\text { Breast pain } \\
\text { (acute) }\end{array}$ & $\begin{array}{c}\text { Breast pain } \\
\text { (late) }\end{array}$ \\
\hline 1 & 0 & 0 & 0 & 0 & 0 & 1 & 0 & 0 & 0 & 0 \\
\hline 2 & 0 & 0 & 0 & 0 & 0 & 0 & 0 & 0 & 0 & 0 \\
\hline 3 & 0 & 0 & 0 & 0 & 0 & 0 & 0 & 1 & 0 & 0 \\
\hline 4 & 0 & 0 & 0 & 2 & 1 & 2 & 0 & 0 & 0 & 0 \\
\hline 5 & 1 & 0 & 2 & 0 & 2 & 0 & 0 & 1 & 0 & 0 \\
\hline 6 & 0 & 0 & 0 & 0 & 0 & 0 & 0 & 0 & 0 & 0 \\
\hline 7 & 1 & 0 & 2 & 2 & 2 & 2 & 0 & 0 & 1 & 0 \\
\hline 8 & 1 & 0 & 0 & 0 & 0 & 0 & 0 & 0 & 0 & 0 \\
\hline 9 & 0 & 1 & 0 & 0 & 1 & 2 & 0 & 1 & 0 & 0 \\
\hline 10 & 0 & 1 & 0 & 3 & 1 & 2 & 0 & 1 & 0 & 0 \\
\hline 11 & 0 & 1 & 0 & 0 & 0 & 0 & 0 & 0 & 0 & 0 \\
\hline 12 & 0 & 0 & 0 & 0 & 0 & 0 & 0 & 1 & 0 & 1 \\
\hline Total & $25 \%$ & $25 \%$ & $17 \%$ & $25 \%$ & $42 \%$ & $42 \%$ & 0 & $42 \%$ & $8 \%$ & $8 \%$ \\
\hline
\end{tabular}

All toxicity graded per the NCI CTCAE version 4.02; acute defined as within 3 months from intraoperative radiotherapy treatment. 
OS of $94.8 \%$ in a cohort of 58 patients. Four patients underwent subsequent mastectomy, two for a subsequent IBTR, one for a non-healing wound and another patient who underwent bilateral mastectomy after discovery of contralateral disease (30). They describe grade 1 late toxicity (greater than 1 year from treatment) in $24.1 \%$ of patients mainly consisting of breast pain and fibrosis, grade 2 late toxicity in $22.4 \%$, and grade 3 toxicity in $6.9 \%$ with one instance of grade 3 infection. Comparable to the 3-year toxicity data from RTOG 1014, we observed a significant number of grade 2 and 3 toxicities in the late setting.

\section{Limitations}

The major limitations of this study include the retrospective nature of our data with limited follow-up to observe further delayed toxicities and recurrences. Given the small sample population of our study, it is difficult to draw conclusions regarding the differences in toxicity between our PBrI experience and previously published studies. Finally, we did not report on patient satisfaction and quality of life in our study. The pursuit of breast-conservation was driven mainly by patient

\section{REFERENCES}

1. Early Breast Cancer Trialists' Collaborative Group (EBCTCG), Darby S, McGale P, Correa C, Taylor C, Arriagada R, et al. Effect of radiotherapy after breast-conserving surgery on 10-year recurrence and 15-year breast cancer death: meta-analysis of individual patient data for 10,801 women in 17 randomised trials. Lancet (2011) 378:1707-16. doi:10.1016/S01406736(11)61629-2

2. Fisher B, Anderson S, Bryant J, Margolese RG, Deutsch M, Fisher ER, et al. Twenty-year follow-up of a randomized trial comparing total mastectomy, lumpectomy, and lumpectomy plus irradiation for the treatment of invasive breast cancer. N Engl J Med (2002) 347:1233-41. doi:10.1056/ NEJMoa022152

3. Dalberg K, Mattsson A, Sandelin K, Rutqvist LE. Outcome of treatment for ipsilateral breast tumor recurrence in early-stage breast cancer. Breast Cancer Res Treat (1998) 49:69-78. doi:10.1023/A:1005934513072

4. Salvadori B, Marubini E, Miceli R, Conti AR, Cusumano F, Andreola S, et al. Reoperation for locally recurrent breast cancer in patients previously treated with conservative surgery. Br J Surg (1999) 86:84-7. doi:10.1046/ j.1365-2168.1999.00961.x

5. Abner AL, Recht A, Eberlein T, Come S, Shulman L, Hayes D, et al. Prognosis following salvage mastectomy for recurrence in the breast after conservative surgery and radiation therapy for early-stage breast cancer. J Clin Oncol (1993) 11:44-8. doi:10.1200/JCO.1993.11.1.44

6. Voogd AC, van Tienhoven G, Peterse HL, Crommelin MA, Rutgers EJ, van de Velde CJ, et al. Local recurrence after breast conservation therapy for early stage breast carcinoma: detection, treatment, and outcome in 266 patients. Dutch Study Group on Local Recurrence after Breast Conservation (BORST). Cancer (1999) 85:437-46. doi:10.1002/(SICI)1097-0142 (19990115)85:2<437::AID-CNCR23>3.0.CO;2-1

7. Kurtz JM, Jacquemier J, Amalric R, Brandone H, Ayme Y, Hans D, et al. Is breast conservation after local recurrence feasible? Eur J Cancer (1991) 27:240-4. doi:10.1016/0277-5379(91)90505-8

8. Ishitobi $M$, Okumura $Y$, Nishimura R, Nakatsukasa $K$, Tanabe $M$, Yoshida A, et al. Repeat lumpectomy for ipsilateral breast tumor recurrence (IBTR) after breast-conserving surgery: the impact of radiotherapy on second IBTR. Breast Cancer (2014) 21:754-60. doi:10.1007/s12282-013-0454-6

9. Kurtz JM, Spitalier JM, Amalric R, Brandone H, Ayme Y, Jacquemier J, et al. The prognostic significance of late local recurrence after breastconserving therapy. Int J Radiat Oncol Biol Phys (1990) 18:87-93. doi:10.1016/ 0360-3016(90)90271-K

10. Alpert TE, Kuerer HM, Arthur DW, Lannin DR, Haffty BG. Ipsilateral breast tumor recurrence after breast conservation therapy: outcomes of salvage preference, and ultimately the low-grade toxicities we observed with breast conservation may be outweighed by the success of breast preservation.

\section{CONCLUSION}

Breast-conserving surgery with IORT is a feasible salvage option for patients desiring breast conservation after prior thoracic radiation; however, continued follow-up of these patients is warranted given the incidence of delayed treatment toxicity. Further studies are needed to determine optimal treatment strategy, dose, and dose fractionation for PBrI.

\section{AUTHOR CONTRIBUTIONS}

Each of the listed authors contributed to the completion of this submission. Both CC and PJ worked on data collection and drafting of the final manuscript. BT, SF, RH, DH, and EC all contributed to the critical revision of the article with final approval for publication.

mastectomy vs. salvage breast-conserving surgery and prognostic factors for salvage breast preservation. Int J Radiat Oncol Biol Phys (2005) 63:845-51. doi:10.1016/j.ijrobp.2005.02.035

11. Yoshida A, Takahashi O, Okumura Y, Arima N, Nakatsukasa K, Tanabe M, et al. Prognosis after mastectomy versus repeat lumpectomy in patients with ipsilateral breast cancer recurrence: a propensity score analysis. Eur J Surg Oncol (2016) 42:474-80. doi:10.1016/j.ejso.2016.01.011

12. Kuerer HM, Arthur DW, Haffty BG. Repeat breast-conserving surgery for in-breast local breast carcinoma recurrence: the potential role of partial breast irradiation. Cancer (2004) 100:2269-80. doi:10.1002/cncr.20257

13. Vaidya JS, Wenz F, Bulsara M, Tobias JS, Joseph DJ, Keshtgar M, et al. Risk-adapted targeted intraoperative radiotherapy versus whole-breast radiotherapy for breast cancer: 5-year results for local control and overall survival from the TARGIT-A randomised trial. Lancet (2014) 383:603-13. doi:10.1016/S0140-6736(13)61950-9

14. Strnad V, Hildebrandt G, Pötter R, Hammer J, Hindemith M, Resch A, et al. Accelerated partial breast irradiation: 5-year results of the GermanAustrian multicenter phase II trial using interstitial multicatheter brachytherapy alone after breast-conserving surgery. Int J Radiat Oncol Biol Phys (2011) 80:17-24. doi:10.1016/j.ijrobp.2010.01.020

15. Veronesi $U$, Orecchia $R$, Maisonneuve $P$, Viale G, Rotmensz N, Sangalli $\mathrm{C}$, et al. Intraoperative radiotherapy versus external radiotherapy for early breast cancer (ELIOT): a randomised controlled equivalence trial. Lancet Oncol (2013) 14:1269-77. doi:10.1016/S1470-2045(13)70497-2

16. Vaidya JS, Vyas JJ, Chinoy RF, Merchant N, Sharma OP, Mittra I. Multicentricity of breast cancer: whole-organ analysis and clinical implications. Br J Cancer (1996) 74:820-4. doi:10.1038/bjc.1996.442

17. Deutsch M. Repeat high-dose external beam irradiation for in-breast tumor recurrence after previous lumpectomy and whole breast irradiation. Int JRadiat Oncol Biol Phys (2002) 53:687-91. doi:10.1016/S0360-3016(02) 02785-2

18. Hannoun-Levi JM, Resch A, Gal J, Kauer-Dorner D, Strnad V, Niehoff P, et al. Accelerated partial breast irradiation with interstitial brachytherapy as second conservative treatment for ipsilateral breast tumour recurrence: multicentric study of the GEC-ESTRO Breast Cancer Working Group. Radiother Oncol (2013) 108:226-31. doi:10.1016/j.radonc.2013. 03.026

19. Resch A, Fellner C, Mock U, Handl-Zeller L, Biber E, Seitz W, et al. Locally recurrent breast cancer: pulse dose rate brachytherapy for repeat irradiation following lumpectomy - a second chance to preserve the breast. Radiology (2002) 225:713-8. doi:10.1148/radiol.2253011913

20. Chadha M, Feldman S, Boolbol S, Wang L, Harrison LB. The feasibility of a second lumpectomy and breast brachytherapy for localized cancer in a 
breast previously treated with lumpectomy and radiation therapy for breast cancer. Brachytherapy (2008) 7:22-8. doi:10.1016/j.brachy.2007.10.006

21. Guix B, Lejárcegui JA, Tello JI, Zanón G, Henríquez I, Finestres F, et al. Exeresis and brachytherapy as salvage treatment for local recurrence after conservative treatment for breast cancer: results of a ten-year pilot study. Int J Radiat Oncol Biol Phys (2010) 78:804-10. doi:10.1016/j.ijrobp.2009.08.009

22. Kauer-Dorner D, Pötter R, Resch A, Handl-Zeller L, Kirchheiner K, Meyer-Schell K, et al. Partial breast irradiation for locally recurrent breast cancer within a second breast conserving treatment: alternative to mastectomy? Results from a prospective trial. Radiother Oncol (2012) 102:96-101. doi:10.1016/j.radonc.2011.07.020

23. Polgar C, Major T, Sulyok Z, Frohlich G, Szabo E, Savolt A, et al. [Second breast-conserving surgery and reirradiation with interstitial high-dose-rate brachytherapy for the management of intra-breast recurrences - 5-year results]. Magy Onkol (2012) 56:68-74.

24. Keshtgar MR, Vaidya JS, Tobias JS, Wenz F, Joseph D, Stacey C, et al. Targeted intraoperative radiotherapy for breast cancer in patients in whom external beam radiation is not possible. Int J Radiat Oncol Biol Phys (2011) 80:31-8. doi:10.1016/j.ijrobp.2010.01.045

25. Kraus-Tiefenbacher U, Bauer L, Scheda A, Schoeber C, Schaefer J, Steil V, et al. Intraoperative radiotherapy (IORT) is an option for patients with localized breast recurrences after previous external-beam radiotherapy. BMC Cancer (2007) 7:178. doi:10.1186/1471-2407-7-178

26. Hammond ME, Hayes DF, Dowsett M, Allred DC, Hagerty KL, Badve S, et al. American Society of Clinical Oncology/College Of American Pathologists guideline recommendations for immunohistochemical testing of estrogen and progesterone receptors in breast cancer. J Clin Oncol (2010) 28:2784-95. doi:10.1200/JCO.2009.25.6529

27. Wolff AC, Hammond ME, Hicks DG, Dowsett M, McShane LM, Allison KH, et al. Recommendations for human epidermal growth factor receptor 2 testing in breast cancer: American Society of Clinical Oncology/College of American Pathologists clinical practice guideline update. Arch Pathol Lab Med (2014) 138:241-56. doi:10.5858/arpa.2013-0953-SA

28. Evans SB, Kaufman SA, Price LL, Cardarelli G, Dipetrillo TA, Wazer DE. Persistent seroma after intraoperative placement of MammoSite for accelerated partial breast irradiation: incidence, pathologic anatomy, and contributing factors. Int J Radiat Oncol Biol Phys (2006) 65:333-9. doi:10.1016/j.ijrobp.2005.12.045

29. Kraus-Tiefenbacher U, Welzel G, Brade J, Hermann B, Siebenlist K, Wasser KS, et al. Postoperative seroma formation after intraoperative radiotherapy using low-kilovoltage X-rays given during breast-conserving surgery. Int J Radiat Oncol Biol Phys (2010) 77:1140-5. doi:10.1016/j.jirobp.2009. 06.008

30. Arthur DW, Moughan J, Kuerer HM, Haffty BG, Cuttino LW, Todor DA, et al. NRG oncology/RTOG 1014: 3 year efficacy report from a phase II study of repeat breast preserving surgery and 3D conformal partial breast re-irradiation (PBrI) for in-breast recurrence. Int J Radiat Oncol Biol Phys (2016) 96:941. doi:10.1016/j.ijrobp.2016.09.054

Conflict of Interest Statement: The authors declare that the research was conducted in the absence of any commercial or financial relationships that could be construed as a potential conflict of interest.

Copyright (๑ 2017 Chin, Jadeja, Taback, Horowitz, Feldman, Ha and Connolly. This is an open-access article distributed under the terms of the Creative Commons Attribution License (CC BY). The use, distribution or reproduction in other forums is permitted, provided the original author(s) or licensor are credited and that the original publication in this journal is cited, in accordance with accepted academic practice. No use, distribution or reproduction is permitted which does not comply with these terms. 